\title{
Somogy megye vízibogarainak katalógusa (Coleoptera: Haliplidae, Dytiscidae, Noteridae, Gyrinidae, Spercheidae, Hydrochidae, Helophoridae, Hydrophilidae, Hydraenidae)
}

\author{
CSABAI ZOLTÁN
}

CSABAl, Z.: Catalogue of the aquatic beetle fauna of Somogy county (Coleoptera: Haliplidae, Dytiscidae, Noteridae, Gyrinidae, Spercheidae, Hydrochidae, Helophoridae, Hydrophilidae, Hydraenidae)

Abstract: At the moment 51 genus, 180 species of aquatic beetles (13 Haliplidac, 78 Dytiscidac, 2 Noteridae, 6 Gyrinidae, 1 Spercheidae, 5 Hydrochidae, 8 Helophoridae, 61 Hydrophilidae, 6 Hydraenidae) are known in the fauna of Somogy county; it is more than 68 percentage of the Hungarian water beetle fauna.

\section{Bevezetés}

Elsô ízben PoLiNszKY (1886) tesz említést Somogy megye területén gyújtött vízibogarakról: négy faj előfordulását közli. A Fauna Regni Hungariae Coleoptera kötetében (KUTHY I 897) egyetlen tárgyalt család vonatkozásában sem találunk Somogy megyei lelöhelyadatot. CSIKI (1946) összefoglaló munkájában két faj előfordulását említi.

Somogy megyében az elsô komplex jellegú faunafeltárást célzó vizsgálat 1975-tól a Barcsi Borókás TK kutatása volt. Ennek keretében HorvATOVICH (1981b) számol be a tájvédelmi körzet Dytiscidae faunájáról. További közleményeiben (HORVATOVICH 1979, 1980, 1981a) is említi a területról elókerült ritkább fajokat.

A közelmúltban GIDó és SzÉl (1998) új gyưjtési adatok közlése mellett, öszszefoglalta a Duna-Dráva Nemzeti Park Dráva menti részéról származó irodalmi és gyújteményi adatokat. A közleményben 125 faj Somogy megyei elófordulási adatát ismertették.

A Somogy megyében végzett faunisztikai vizsgálatok során elókerült számos olyan ritka faj, amelyek adatait a magyar irodalom - e fajok újabb elókerüléséról beszámolva - gyakran idézi (ÁDÂM 1986, 1993, CsABAI et al. 1999, CsABAI 2000).

ENDRÓDY-YOUNG^ (1967) az Ochthebius adriaticus Reitter, 1886 siófoki elófordulását közli, majd ezt az adatot TóTH (1991) is átveszi. Mindkét említés az MTM gyújteményében elhelyezett, Lichneckert által gyújtött, valóban a kérdéses fajhoz tartozó egyetlen régi példányon alapul. A faj kizárólag az Adria vidékén honos, így nagy valószínúséggel hibás cédulázásról van szó (Csabai és SzÉl 1999), ezért a fajt nem szerepeltettem a listában.

Ugyancsak nem szerepelnek a jegyzékben a téves határozáson alapuló, késóbbiekben revideált adatok. A HORVATOVICH (1981a, b) által közölt, GiDó és 
SzÉl (1998) által is átvett Hydroporus umbrosus (Gyllenhal, 1808) adat valójában Hydroporus neglectus Schaum, 1845 példányt takar. Ugyancsak HorvarovicH (1981b) közölte a Dytiscus circumcinctus Ahrens, $181 \mathrm{l}$ és Rhantus exoletus (Forster, 1771) fajokat, amelyek szintén téves határozás eredményei (D. circumflexus Fabricius, 1801 és Rh. latitans Sharp, 1882). Téves határozás a Gidó és SzÉl (1998) által közölt és CSABAI és SzÉl (1999) által is átvett Helophorus flavipes Fabricius, 1792 faj potonyi adata is (Gidó Zsolt szóbeli közlése).

A Mátra Múzeum (Gyöngyös) bogárgyújteményeinek anyagát Ánর́M (1994) illetve CsABAI et al. (2001) részletesen feldolgozták. A Déri Múzeum (Debrecen) gyújteményében nem találtam Somogy megyéból származó példányt. A Janus Pannonius Múzeum (Pécs) gyúiteményéról Ábím (1996), valamint GII)o és SzÉl (1998) nyújt összefoglalást, a késóbbiekben a gyújteményben elhelyezett, Gidó Zsolt 1999-es Dráva menti gyứitéseiból származó példányok adatait coll: JPM rövidítéssel jelöltem a listában. A Magyar Természettudományi Múzeum (Budapest) bogárgyújiteményének (rövidítve: coll: MTM) vonatkozó részeit is áttekintettem. Csak abban az esetben tüntettem fel gyújteményi példányt, ha az adott faj esetében nincs publikált, Somogy megyéból származó adat. További gyújitemények feldolgozására a jelen keretek között nem nyílt lehetôségem.

Néhány faj esetében a Somogy megyei elófordulást csak Lichneckert által gyuuijtött siófoki cédulázású példányok bizonyítják. Ezek eredete kétséges, így az ilyen fajokat kérdéses adatként (rövidítve: KA) kezeltem.

Több irodalmi adat esetében előfordul az, hogy a szerzô az adott fait nem a jelenleg érvényes néven közölte, jelen munkában ennek említésére külön nem tértem ki, a szinonímaviszonyok CSABAI (2000), illetve CSABAI és SzÉL (1999) munkájában részletesen megtalálhatók.

Bár nem a szó szoros értelmében vízibogarak, rendszertani okokból a nagyrészt szárazföldi életmódú Sphaeridiinae alcsalád (Hydrophilidae) fajait is jelen cikk tárgyalja.

A megye egyes területei igen eltérô mértékben kutatottak. A vízibogár-faunát tekintve a Barcsi-Ôsborókás az egyetlen kielégítóen feltárt terület. Aránylag nagy számú adattal rendelkezünk a Dráva menti területek néhány vízterébôl, illetve a Balaton déli partjának egyes területeiról (Fonyód, Vörs, Zamárdi), ugyanakkor a megye többi részéról mindössze szórványadataink vannak, amelyek jó része csak régi, sokszor a századforduló környékéról származó példányokon alapul.

Napjainkig Somogy megyéból az érintett családokból 51 génusz 180 fajának elófordulása ismert, amely a magyar faunának több, mint 68 százaléka.

A Gyrinus marinus Gyllenhal, 1808 és a Berosus geminus Reiche \& Saulcy, 1856 magyarországi elófordulását mindössze egy-egy Somogy megyei példány bizonyítja (ÁdÁm 1992, CsABA és SzÉl 2000).

A Haliplus fulvus (Fabricius, 1801), a Hydroporus discretus ponticus Zaitzev, 1927, a Hydroporus hebaueri Hendrich, 1990, a Hygrotus pallidulus (Aubé, 1850), a Laccornis kocae (Ganglbauer, 1904), az Agabus biguttatus (Olivier, 1795), az Agabus labiatus (Brahm, 1790), az Agabus nebulosus (Forster, 1771), az Agabus paludosus (Fabricius, 1801), az Aulonogyrus concinnus (Klug, 1834), a Gyrinus marinus Gyllenhal, 1808, a Hydrochus brevis Herbst, 1793, a Hydrochus carinatus Germar, 1824, a Helophorus obscurus Mulsant, 1844 és a Helophorus redtenbacheri Kuwert, 1885 fajoknak csak régi adatait ismerjük a megyéböl, az utóbbi 50 évben nem kerültek elô. 


\section{Somogyból ismert fajok jegyzéke}

Haliplidae

Haliplus flaricollis Sturm, 1834 - Gidó és Szél (1998).

Haliplus fluviatilis Aubé, 1836 - Merkl (1996), Gidó és Szél (1998).

Haliplus fulvicollis Erichson, 1837 - Ádám (1996), Gidó és Szél (1998), Csabai et al. (1999), Csabai (2000).

Haliplus fulpus (Fabricius, 1801) - coll: MTM.

Haliplus furcatus Seidlitz, 1887 - Csiki (1946).

Haliplus heydeni Wehncke, 1875 - Ádám (1996), Gidó és Szél (1998). JPM.

Haliplus immaculatus Gerhardt, 1877 - coll:

Haliplus laminatus (Schaller, 1783)-coll: JPM. Haliplus lineatocollis (Marsham, 1802) Gidó és Szél (1998).

Haliplus obliquus (Fabricius, 1787) - Ádám (1996).

Haliplus ruficollis (De Geer, 1774) Polinszky (1886), Merkl (1996), Gidó és Szćl (]998).

Haliplus variegatus Sturm, 1834 - coll: MTM.

Peltodytes caesus (Duftschmid, 1805) Ádám (1996), Merkl (1996), Gidó és Szél (1998), Csabai et al. (2001).

\section{Dytiscidae}

Copelatus haemorrhoidalis (Fabricius, 1787) Horvatovich (1981b), ^́dám (1996), Gidó és Szél (1998).

Hydroglyphus geminus (Fabricius, 1792) Horvatovich (1981b), Ádám (1996), Gidó és Šél (1998), Csabai et al. (2001).

Bidessus nasutus Sharp, 1887 - Horvatovich (1981b), Gidó és Szél (1998).

Bidessus unistriatus (Goeze, 1777) Horvatovich (1981b), Ádám (1996), Gidó és Szél (1998).

Hygrotus decoratus (Gyllenhal, 1808) Horvatovich (1981b), Ádám (1996), Gidó és Szél (1998).

Hygrotus impressopunctatus (Schaller, 1783) - Horvatovich (1981b), ヘ́dám (1996), Gidó és Szél (1998), Csabai et al. (2001).

Hygrotus inaequalis (Fabricius, 1776) Horvatovich (1981b), Ádám (1996), Gidó és Szél (1998), Csabai et al. (2001).

Hygrotus pallidulus (Aubé, 1850) - ヘ́dám (1992), Csabai (2000) - KA.
Hygrotus parallellogrammus ( $\mathrm{h}$ hrens, 1812)Csabai et al. (2001).

Hygrotus versicolor (Schaller, 1783) - coll: JPM.

Graptodytes bilineatus (Sturm, 1835) Horvatovich (1981b), Ádám (1996), Gidó és Szćl (1998).

Graptodytes granularis (Linnacus, 1767) Polinszky (1886), Horvatovich (1981a, b), Ádám (1996), Gidó és Szél (1998).

Graptodytes pictus (Fabricius, 1787) - Gidó és Szél (1998).

Hydroporus angustatus Sturm, 1835 Horvatovich (1981 a, b), Ádám (1996), Gidó és Szél (1998).

Hydroporus discretus discretus Fairmaire \& Brisout, 1859 - Horvatovich (1981b), Ádám (1993), Gidó és Szél (1998), Csabai (2000).

Hydroporus discretus ponticus Zaitzev, 1927 Ádám (1993), Csabai (2000).

Hydroporus erythrocephalus (Linnaeus, 1758) - Ádám (1996), Gidó és Szél (1998).

Hydroporus fuscipennis Schaum, 1868 ńdám (1996), Gidó és Szél (1998).

Hydroporus hebaueri Hendrich, 1990 Ádám (1986), Csabai (2000).

Hydroporus melanarius Sturm, 1835 Horvatovich (1981a), 1981b, Ádám (1996), Gidó és Szél (1998), Csabai (2000).

Hydroporus neglectus Schaum, 1845 - ヘ́dám (1996), Gidó és Szél (1998), Csabai (2000).

Hydroporus nigrita (Fabricius, 1792) Horvatovich (1981b), Gidó és Szél (1998).

Hydroporus notatus Sturm, 1835 Horvatovich (1981 a, b), Ádám (1996), Gidó és Szél (1998), Csabai (2000).

Hydroporus palustris (Linnacus, 1761) Horvatovich (1981b), Ádám (1996), Gidó és Szél (1998).

Hydroporus planus (Fabricius, 1781) Horvatovich (1981b), Ádám (1996), Gidó és Szél (1998).

Hydroporus scalesianus Stephens, 1828 Csabai (2000).

Hydroporus striola (Gyllenhal, 1826) Ádám (1992, 1996), Gidó és Szél (1998).

Hydroporus tristis (Paykull, 1798) Horvatovich (1979, 1980, 1981b), 亿́dám (1996), Gidó és Szćl (1998).

Porhydrus lineatus (Fabricius, 1775) Horvatovich (1981b), Ádám (1996), Gidó és Szćl (1998), Csabai et al. (2001). 
Porhydrus obliquesignatus (Biclz, 1852) coll: MTM.

Scarodytes halensis (Fabricius, 1787) - Csabai el al. (2001).

Suphrodytes dorsalis (Fabricius, 1787) Horvatovich (1980), 1981b, Ádám (1996), Gidó és Szél (1998), Csabai et al. (2001).

Lacconis kocae (Ganglbaucr, 1904) - coll: MIM.

Hyphydrus anatolicus Guignol, 1957 Ádám (1992), Csabai (2000).

Hyphydrus opatus (Limnacus, 1761) Horvatovich (1981b), Ádám (1996), Gidó és Szél (1998), Csabai et al. (2001).

Hydrovatus cuspidatus (Kunze, 1818) - coll: MIM.

Laccophilus hyalinus (De Geer, 1774) Merkl (1996).

Laccophilus minutus (Linnaeus, I758) Horvalovich (1981b), Ádám (1996), Gidó és Srél (1998).

Laccophilus poecilus Klug, 1834 Horvatovich (1981b), Ádám (1996), Gidó és Szćl (1998).

Agabus biguttatus (Olivier, 1795) - coll: MTM - KA.

Agabus bipustulatus (Linnaeus, 1767) Horvatovich (1981b), Ádám (1994, 1996), Gidó és Szél (1998), Csabai et al. (2001).

Agabus chalconatus (Panzer, 1797) Horvatovich (1981b), Ádám (1996), Gidó és Szél (1998), Csabai êt al. (2001).

Agabus guttatus (Paykull, 1798) Horvatovich (1981b), Gidó és Szél (1998).

Agabus labiatus (Brahm, 1790) - coll: MTM - KA.

Agrabus nebulosus (Forster, 1771) - coll: MTM - KA.

Agabus neglectus Erichson, 1837 - Ádám (1996), Csabai (2000).

MTM

Agabus paludosus (Fabricius, 1801) - coll:

Agabus subtilis Erichson, 1837 - ヘ́dám (1986, 1996), Gidó és Szél (1998), Csabai $(2000)$.

Agabus striolatus (Gyllenhal, 1808 ) Horvatovich (1981a), 1981b, Ádám (1986), 1996, Gidó és Szél (1998), Ćsabai (2000).

Agabus wliginosus (Linnacus, 176I) - Ádám (1996), Gidó és Szél (1998).

Agabus undulatus (Schrank, 1776) Horvatovich (198Ib), Ádám (1996), Gidó és Szél (1998), Csabai et al. (2001).

Platambus maculatus (Linnaeus, 1758) Gidó és Śzél (1998), Csabai et al. (2001).
Ilybius ater (De Geer, 1774) - Horvatovich (1981b), Ádám (1994, 1996), Gidó és Šél (1998)

Ilybius fenestratus (Fabricius, 1781) - Ádám (1996), Gidó és Szél (1998), Csabai et al. (2001).

Ilybius fuliginosus (Fabricius, 1792) Horvatovich (1981b), Ádám (1996), Gidó és Szél (1998).

Ilybius guttiger (Gyllenhal, 1818) - Ádám (1992), Csabai $(2000)$.

Ilybius quadriguttatus (Lacordaire, I835) Horvatovich (1981b), Ádám (1996), Gidó és Szél (1998).

Ilybius subaeneus Erichson, 1837 - Csiki (1946), Horvatovich (1980), Ádám (1996), Gidó és Szél (1998).

Rhantus bistriatus (Bergsträsscr, 1778) Gidó és Szél (1998). Mil'M.

Rhantus consputus (Sturm, 1834) - coll:

Rhantus frontalis (Marsham, 1802) Horvatovich (1981b), ^́dám (1996), Gidó és Szél (I998).

Rhantus grapii (Gyllenhal, I808) - Gidó és Szél (1998).

Rhantus latitans Sharp, 1882 - Ádám (1996), Gidó és Szél (1998).

Rhantus suturalis (MacLeay, I825) Horvatovich (1980, I981b), Ádám (1996), Gidó és Szél (1998), Csabai et al. (200I).

Colymbetes fuscus (Linnaeus, 1758) Horvalovich (1981b), Ádám (1996), Gidó és Szél (1998).

Hydaticus grammicus (Germar, 1830) Horvatovich (1981a), 1981b, ヘ́dám (1996), Gidó és Szél (I998).

Hydaticus seminiger (De Geer, 1774) Horvatovich (1981b), Ádám (1996), Gidó és Szél (1998), Csabai et al. (2001).

Hydaticus transpersalis (Pontoppidan, 1763) - Ádám (1996), Gidó és Szél (1998), Csabai ct al. $(200 \mathrm{l})$

Graphoderus austriacus (Sturm, 1834) Ádám (1996), Gidó és Sxúl (1998).

Graphoderus cinereus (Linnacus, 1758) Ádám (1996).

Graphoderus zonatus (Hoppe, 1795) - coll: MTM.

Acilius canaliculatus (Nicolai, 1822) - Gidó és Szçl (1998).

Acilius sulcatus (Linnaeus, 1758) - Ádám (1994), Merkl (1996), Gidó és Szél (1998).

Dytiscus circumcinctus Ahrens, 1811 - coll: MTM. 

JPM.

Dytiscus circumflexus Fabricius, 1801 - coll:

Dytiscus dimidiatus Bergsträsser, 1778 Horvatovich (1981b), Ádám (1996), Gidó és Szćl (1998).

Dytiscus marginalis Linnaeus, 1758 - Ádám (1996), Merkl (1996), Gidó és S7ćl (1998).

Cybister lateralimarginalis (De Geer, 1774) Horvatovich (1981b), Ádám (1996), Gidó és Szél (1998).

\section{Noteridae}

Noterus clavicornis (Dc Geer, 1774) Horvatovich (198Ib), Ádám (1996), Merkl (1996), Ciidó és Szél (1998), Csabai et al. $(2001)$.

Noterus crassicornis (O.F.Müller, 1776) Horvatovich (1981b), Ádám (1996), Merkl (1996), Gidó és Szél (1998), Csabai et al. (2001).

\section{Gyrinidae}

Aulonogyrus concinnus (Klug, 1834) - Ádám (1992), Csabai (2000) - KA.

Gyrinus distinctus Aubé, 1836 - Ádám (1994).

Gyrinus marinus Gyllenhal, 1808 - ヘ́dám (1992), Csabai (2000) - KA.

Gyrinus paykulli (Ochs, 1927) - coll: JPM.

Gyrinus substriatus Stephens, 1829 - Ádám (1994, 1996), Gidó és Szél (1998), Csabai et al. (2001).

Orectochilus villosus (O.F.Müller, 1776) - Kovács et al. (2000).

\section{Spercheidae}

Spercheus emarginatus (Schaller, 1783) Gidó és Szzél (1998).

\section{Hydrochidae} MTM

Hydrochus angustatus Germar, 1824 - coll: - KA.

Hydrochus brevis Herbst, 1793 - coll: MTM

Hydrochus carinatus Germar, 1834 - Gidó és Szél (1998).

Hydrochus elongatus (Schaller, 1783) - Gidó és Szcél (1998).

Hydrochus megaphallus Berge Henegouwen, 1988 - Merkl (1996), Csabai és Szél (1999).

\section{Helophoridae}

Helophorus aquaticus (Linnaeus, 1758) Gidó és Szél (1998).

Helophorus breripalpis Bedel, 1881 - Gidó és Szél (1998).
Helophorus granularis (Linnaeus, 1761) Polinszky (1886), Gidó és Szél (1998).

Helophorus longitarsis Wollaston, 1864 Endrôdy-Younga (1967), Tóth (1991).

Helophorus montenegrinus Kuwert, 1885 Gidó és Szél (1998).

Helophorus nubilus Fabricius, 1776 - Gidó és Szél (1998).

Helophorus obscurus Mulsant, 1844 - coll: MTM - KA.

Helophorus redtenbacheri Kuwert, 1885 coll: M'TM - KA.

\section{Hydrophilidae}

Coelostoma orbiculare (Fabricius, 1775) Merkl (1996), Gidó és Szél (1998).

Sphaeridium bipustulatum Fabricius, 1781 Gidó és Szél (1998).

Sphaeridium lunatum Fabricius, 1792 Horvatovich (1980), Gidó és Szél (1998).

Sphaeridium scarabaeoides (Linnaeus, 1758) - Gidó és Szél (1998).

Sphaeridium substriatum Faldermann, 1838 - Gidó és Szél (1998).

Cercyon analis (Paykull, 1798) - coll: MTM.

Cercyon bifenestratus Küster, 1851 - Gidó és

Szél (1998).

Cercyon contexiusculus Stephens, 1829 Gidó és Szél (1998).

Cercyon granarius Erichson, 1837 - coll: МТМ.

Cercyon haemorrhoidalis (Fabricius, 1775) coll: MTM.

Cercyon hungaricus Endrödy-Younga, 1968 Endrődy-Younga (1967, 1968, 1969), Gidó és Szél (1998), Csabai és Szél (1999) - KA.

Cercyon impressus (Sturm, 1807) - EndrödyYounga (1967).

Cercyon laminatus Sharp, 1873 - Gidó és Szzél (1998).

Cercyon lateralis (Marsham, 1802) - Gidó és Szél (1998).

Cercyon marinus Thomson, 1853 - Gidó és Szél (1998). MTM.

Cercyon nigriceps (Marsham, 1802) - coll:

Cercyon obsoletus (Gyllenhal, 1808) Endrödy-Younga (1967). MTM

Cercyon pygmaeus (Illiger, 1801) - coll:

Cercyon quisquilius (Linnaeus, 176I) - Gidó és Szzél (1998).

Cercyon sternalis Sharp, 1918 - Gidó és Szél (1998). 

MTM

Cercyon terminatus (Marsham, 1802) - coll:

Cercyon tristis (Illiger, 1801) - Gidó és Szél (1998).

Cercyon unipunctatus (Linnaeus, 1758) Gidó és Szél (1998).

Cercyon ustulatus (Proyssler, 1790) - coll: Mi'M.

Cryptopleurum crenatum (Panzer, 1794) coll: M'TM.

Cryptopleurum minutum (Fabricius, 1775) Ciidó és Szćl (1998).

Cryptoplewrum subtile Sharp, 1884 - Gidó és Szél (1998), Csabai és Szél (1999).

Megasternum obscurum (Marsham, 1802) Gidó és Sxćl (1998).

Hydrobius fuscipes (Linnaeus, 1758) - Merkl (1996), Gidó és Szél (1998).

Limnoxenus niger (Zschach, 1788) - Gidó és Szél (1998).

Anacaena globulus (Paykull, 1798) - Gidó és Szól (1998).

Anacaena limbata (Fabricius, 1792) - Merkl (1996), Ciidó és Szćl (1998).

Anacaena lutescens (Stephens, 1829) - Gidó és Szél (1998).

Laccobius bipunctatus (Fabricius, 1775) (Gidó és Syél (1998).

Laccobius gracilis Motschulsky, 1855 - Gidó és Szól (1998).

Laccobius minutus (Linnaeus, 1758) - Merkl (1996), Gidó és Szél (1998). MIM.

Laccobius obscuratus Rottenberg, I 874 - coll:

Laccobius simulatrix d Orchymont, 1932 Gidó és Srćl (1998).

Laccobius sinuatus Motschulsky, 1849 Endródy-Younga (1967), Tóth (1991), Gidó és Szcól (1998).

Laccobius striatulus (Fabricius, 1801) - Gidó és Szćl (1998).

Laccobius syriacus Guillebeau, 1896 Endrödy-Younga (1967), 'Tóth (1991).

Enochrus affinis (Thunberg, 1794) - Gidó és Szćl (1998).

Enochrus bicolor (Fabricius, 1792) - Merkl (1996), Gidó és Szél (1998).

Enochrus coarctatus (Grodler, 1863) - Merkl (1996), Gidó és Szél (I998).

\section{JPM.}

Enochrus fuscipennis ('lhomson, 1884) - coll

Enochrus melanocephalus (Olivier, 1792)Gidó és Szél (1998).

Enochrus ochropterus (Marsham, 1802) Gidó és Szél (1998).

Enochrus quadripunctatus (Herbst, 1797) Merkl (1996), Gidó és Szél (1998).

Enochus testaceus (Fabricius, 1801) - Merkl (1996), Cidó és Szól (1998).

Helochares lividus (Forster, 1771) -

Polinszky (I886), Gidó és Szćl (1998).

Helochares obscumis (O.F.Müller, 1776) -

Mcrkl (1996), Gidó és Szél (1998).

Cymbiodyta marginella (Fabricius, 1792) Merkl (1996), Gidós és Szél (1998).

Chaetarthria seminulum (Herbst, 1797) -

Gidó és Szćl (1998).

Hydrochara caraboides (Limnacus, 1758) Mcrkl (1996), Gidó és Szćl (1998).

Hydrochara flavipes (Stcven, 1808) - Gidó es Srél (1998).

Hydrophilus ater7imus Eschscholt\%, 1822 -

Merkl (1996), Gidó és Szél (1998).

Hydrophilus piceus (Linnaeus, 1758) -

Polinszky (1886), Gidó és Szél (1998).

Berosus geminus Reiche \& Saulcy, 1856 -

Csabai és Szól (1999).

Berosus luridus (Linnacus, 1761) - Cidó és Szćl (1998).

Berosus frontiforeatus Kuwert, 1890 - Gidó és Szél (1998).

Berosus signaticollis (Charpenicr, I825) Gidó és Sról (1998).

\section{Hydraenidae}

Hydraena palustris Erichson, 1837 - Gidó és Szél (1998).

Aulacochthebius narentinus (Reitter, 1885) -

Endrödy-Younga (1967), Tóth (1991).

Ochthebius minimus (Fabricius, 1792) -

Merkl (1996), Gidó és Szćl (1998).

Limnebius aluta Bedel, 1881 - Endrödy-

Younga (1967), Tóth (1991), Gidó és Szél (1998).

Limnebius crinifer Rcy, 1885 - (ridó és Szćl

(1998).

Limnebius papposus Mulsant, 1844 - Gidó és Szél (1998). 


\section{1. táblázat: Somogy faunájából és Magyarországról ismert vízibogárfajok családonkénti megoszlása}

\begin{tabular}{|l|c|c|}
\hline \multirow{2}{*}{ Család } & \multicolumn{2}{|c|}{ Fajszám } \\
\cline { 2 - 3 } & Somogy & Magyarország \\
\hline Haliplidae & 13 & 15 \\
\hline Dytiscidac & 78 & 104 \\
\hline Noteridae & 2 & 2 \\
\hline Gyrinidac & 6 & 9 \\
\hline Spercheidac & 1 & 1 \\
\hline Hydrochidac & 5 & 7 \\
\hline Helophoridae & 8 & 23 \\
\hline Hydrophilidac & 61 & 71 \\
\hline Hydracnidae & 6 & 37 \\
\hline Összesen & 180 & 269 \\
\hline
\end{tabular}

\section{Irodalom}

ÁDÁm, L. 1986: Adephaga of the Kiskunság National Park, II: Dytiscidae-Gyrinidac (Coleoptera). - In: Mahunka, S. (szerk.): The Fauna of the Kiskunság National Park I., Akadémiai Kiadó, Budapest, pp. I43-151.

ヘ́ıภ́M, L. 1992: Faunaterületünk ritkább vízibogarai (Coleoptera: Haliplidae, Gyrinidac, Dytiscidae, Hydroporidae). - Folia ent. hung. 52: 189-195.

ÁbÁm, L. 1993: Haliplidae, Gyrinidac, Noteridae, Dytiscidae, Laccophilidae and Hydroporidae (Coleoptera) of the Bükk National Park. - In: Mahunka, S. (szerk.): The Fauna of the Bükk National Park I., Hungarian Natural History Museum, Budapest, pp. 77-87.

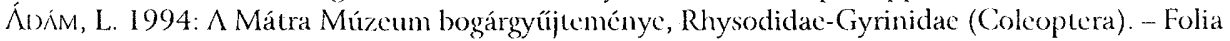
Hist.-nat. Mus. Matr. 19: 129-136.

ÁDX́M, L. 1996: A Janus Paannonius Múzeum vízibogár gyúijteménye (Coleoptera: Haliplidae, Gyrinidac, Dytiscidae, Laccophilidae, Noteridae, Hydroporidae). - A Janus Pannonius Múzeum Évkönyve (1995) 40: 13-17.

CSABA, Z. 2000): Vízibogarak kishatározója I. - Vízi természet- és környezetvédelem sor. 15. köt., Kömyezetgazdálkodási Intézet, Budapest, $277 \mathrm{pp}$.

Csıizn, Z., Ginó, Zs., Juhísz, P., Kiss, B. és Olıjos, P. 1999: Adatok a Körös-Maros Nemzeti Park illetékességi területének vízibogár-faunájához (Coleoptera: Haliplidae, Dytiscidae, Noteridae, Gyrinidae, Hydrochidae, Helophoridae, Hydrophilidae). - Crisicum II. (A Körös-Maros Nemzeti l’ark Igazgatóság idôszaki kiadványa), 141-155.

CSABAI, Z., KovÁcs, T. és AMBruS, A. 2001: Adatok Magyarország vízibogár-faunájához (Colcoptera: Haliplidac, Dytiscidac, Noteridac, Gyrinidae). - Folia Hist.-nat. Mus. Matr 25:00-00 (in press).

CsıbAi, Z. és SzÉl, Gy. 1999: Checklist of Spercheidac, Hydrochidae, Helophoridae, Hydrophilidae and Hydraenidae of Hungary (Coleoptera). - Folia ent. hung. 60: 213-230.

(Sik1, E. 1946: Dic Käferfauna des Karpaten-Beckens. I. Band. Allgemeiner leil und Caraboidea. - In: Tasnádi Kubacska, A. (szerk.): Naturwissenschaftliche Monographien IV. Budapest, 798 pp.

Endródy-Younci^, S. 1967: Csíboralkatúak - Pálpicornia. - In: Magyarország Állatvilága (Fauna Hungariac), VI., 10. Akadémiai Kiadó, Budapest, 97 pp.

ENiRÓDY-Youncin, S. 1968: Neuc und weniger bekannte Hydrophiliden aus dem Karpatenbecken (Coleoptera, Hydrophilidac). - Mitt. münch. ent. Ges. 58: 65-77. 
ENIRÖISY-YOUNGiA, S. 1969: Neue und weniger bekannte Hydrophiliden aus dem KarpatenBecken. - Annls. hist.-nat. Mus. natn. Hung. 61: 215-224.

Gidó, Zs. És SzÉl Gy. 1998: Adatok a Duna-I Oráva Nemzeti Park Dráva menti részének vízibogár (Coleoptera: Hydradephaga, Palpiconia, Dryopidae, Elnidae) faumájáról. - Dunántúli Dolgozatok Természettudományi Sorozat 9: 189-202.

Honvлtovic:, S. 1979: Hazánk faunájára új és ritka bogárfajok a Dél- és Nyugat-Dunántúl hól (Coleoptera). - A Janus Pannonius Múzcum Évkönyve (1978) 23: 31 -39.

Horvatovic:H, S. 1980: Hazánk faunájára új és ritka bogárfajok a Dél-és Nyugat-Dunántúlról II. (Coleoptera). - A Janus Pannonius Múzeum Évkönyve (1979) 24: 33-43.

Horvniovich, S. 1981 a: Hazánk faunájára új és ritka bogárfajok a Dél- és Nyugat-Dunántúlról III. (Coleoptera). - $\Lambda$ Janus Pannonius Múzeum Évkönyve (1980) 25: 71 -83.

Horvatovich, S. 198 Ib: A Barcsi Borókás Tájvédelmi Körzet Cicindelái, Carabidái és Dytiscidái (Coleoptera). - Dunántúli Dolgozatok Természettudományi Sorozat 2: 65-79.

Kovác, 1., Heciyessy, G. és Merki, O. (200): Új és ritka bogarak (Colcoptera) Magyarországról II. - Folia Hist.-nat. Mus. Matr. 24: 197-203.

Kurhy, D. 1897 : Coleoptera. - In: A Magyar Birodalom Állatvilága (Fauna Regni Hungariae). Királyi Magyar Természettudonányi Társulat, Budapest, 213 pp.

Merkı, O. 1996: A Balaton vízibogarai (Coleoptera). - Állatt. Közlem. 81: 193-198.

POLINSZKY, E. 1886: Adatok Somogy megye bogárfaunájához. - Rovartani lapok 3: 146-148.

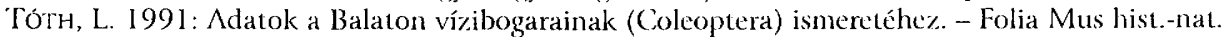
Bakonyensis 10:51-58. 
Catalogue of the aquatic beetle fauna of Somogy county (Coleoptera: Haliplidae, Dytiscidae, Noteridae, Gyrinidae, Spercheidae, Hydrochidae, Helophoridae, Hydrophilidae, Hydraenidae)

\title{
ZOLTÁN CSABAI
}

The first data of aquatic beetles from Somogy county are found in the early paper of PoLINSZKY (1886). Other species were mentioned by CSIKI (1946), HoRvArovich $(1979,1980,1981 \Lambda, 13)$, TóTH (1991), ÁdÁm $(1994,1996)$ and Merke (1996). One of the paratypes of Cercyon hungaricus Endrôdy-Younga, 1968 is from Siófok. Most of the information on aquatic beetles of the county is found in the recently published account of the fauna of the Duna-Dráva National Park (GIDÓ and SzÉl 1998).

At the moment 51 genus, 180 species of water beetles (13 Haliplidae, 78 Dytiscidae, 2 Noteridae, 6 Gyrinidae, I Spercheidae, 5 Hydrochidae, 8 Helophoridae, 61 Hydrophilidae, 6 Hydraenidae) are known in the fauna of Somogy county; it is more than 68 percentage of the Hungarian water beetle fauna.

Gyrinus marinus Gyllenhal, 1808 and Berosus geminus Reiche \& Saulcy, 1856 are known only in Somogy county in Hungary. Haliplus fulvus (Fabricius, 1801), Hydroporus discretus ponticus Zaitzev, 1927, Hydroporus hebaueri Hendrich, 1990, Hygrotus pallidulus (Aubé, 1850), Laccornis kocae (Ganglbauer, 1904), Agabus biguttatus (Olivier, 1795), Agabus labiatus (Brahm, 1790), Agabus nebulosus (Forster, 1771), Agabus paludosus (Fabricius, 1801), Aulonogyrus concinnus (Klug, 1834), Gyrinus marinus Gyllenhal, 1808, Hydrochus brevis Herbst, 1793, Hydrochus carinatus Germar, 1824, Helophorus obscurus Mulsant, 1844 and Helophorus redtenbacheri Kuwert, 1885 were not recorded in Somogy county in the last fifteen years.

\author{
Author's address: \\ Zoltán CSABAI \\ University of Debrecen \\ Department of Ecology \\ H-4010 Debrecen \\ PO. Box 71 . \\ HUNGARY
}

